\title{
PENGARUH SWITCHING COSTS TERHADAP INERTIA DAN CALCULATIVE COMMITMENT STUDI PADA NASABAH CIMB NIAGA CABANG ITC FATMAWATI
}

\author{
Shadiq, TF \\ Universitas Islam Syekh-Yusuf Tangerang Indonesia \\ Email: teuku_fajarshadiq@unis.ac.id
}

\begin{abstract}
The purpose of this study is to examine how the mutual influence between Switching Costs is represented by five variables (benefit lost costs, uncertainty costs, evaluation costs, learning costs and Sunk costs) with Inertia and Calculative Commitment. The objective of this research was to analyze whether there is an impact between the Switching Cost on Inertia and Calculative Commitment which were significantly. This paper presents and develops a model that will articulate and classify the behavior of consumers in the purchase of financial products and services. The theoretical insights generated by this model are then used to examine research data obtained from questionnaires with centralized variables and focus on consumer attitudes towards financial service providers and their financial products. The importance of trust is not explicitly recognized but the relationship between trust and risk largely determines the behavior of a customer Aldas-Manzano et al. (2009). The design of this research applied multiple regression, hypothesis testing of validity (T-test and correlation) and hypothesis testing of reliability (Cronbach's Alpha). Data analysis used in this research was primary data in which the population of this study is CIMB Niaga ITC Fatmawati branch office in South Jakarta. This research was carried out by distributing 200 questionnaires with samples customers who are over three years as a customer and maintain balance actively. The result of this research concluded that there are variables of switching cost that affect are inertia and calculative commitment that is an important driver of behavioral customer. Product innovation competition among actors of financial services to attract new customers must calculate the commitment and customer resistance in the costs and risks that will be generated
\end{abstract}

Keywords: Switching Costs, Benefit Lost Costs, Uncertainty Costs, Learning Costs, Sunk Costs, Inertia, Calculative Commitment,

\section{A. Pendahuluan}

Perubahan regulasi dan kebijakan erat kaitannya dengan hadirnya inovasi baru yang terdorong akibat terciptanya kondisi pasar yang kompetitif dan memiliki dampak pada perilaku konsumen. Kinerja sektor jasa keuangan oleh para penyedia layanan adalah terus berupaya untuk lebih menggali ekspektasi pelanggan tidak hanya untuk mengantisipasi tetapi juga adalah upaya merebut pasar dengan pola mempengaruhi perilaku konsumen.

Konsumen merupakan pihak yang harus dilayani (treatment) dengan baik guna memenuhi kebutuhan (needs) dan kepuasannya (customer satisfaction), 
Kinerja penyedia layanan jasa keuangan harus dilihat secara luas dengan cara menilai keberhasilan dalam memenuhi kebutuhan konsumen. Indikator ukur terkait level loyalitas pelanggan atas pelayanan dalam tahap afektif dinyatakan bahwa antesenden dari loyalitas adalah kepuasan yang berdampak pada loyalitas dan Kepercayaan serta risiko yang dapat teridentifikasi didalam sebuah konstruksi yang saling terkait satu dengan lainnya. (Kassim and Abdulla 2006).

Apa yang perlu dibenahi oleh manajemen didalam memberikan layanannya adalah bagaimana sebuah nilai (value) diperoleh bagi pelanggan dan bagaimana melalui sebuah strategi menciptakan upaya membangun imajinasi pelanggan. Hal ini sejalan dengan (Gronroos (2008), Holbrook (2006), aloza \& Venkatesh (2006) \& Schembri (2006) in Heinonen, (2013), yang menekankan pada perspektif pelanggan. Upaya untuk mencapai keberhasilan bagi sebuah perusahaan atau organisasi yang diwakili manajemen adalah dengan menstimulus bagaimana loyalitas pelanggan dapat di raih.

Arti pentingnya loyalitas pelanggan, merupakan tugas operasionalisasi perusahaan untuk terus berupaya keras agar dapat mempertahankan pelanggannya dalam jangka waktu yang panjang, bahkan tidak mungkin untuk selamanya yang pada akhirnya menciptakan keunggulan dengan penerimaan pendapatan (revenue) yang berkesinambungan. Keinginan pelanggan dalam menggunakan layanan pada hakikatnya menjadi domain dari sosiologi berbasis pendekatan, seperti dalam teori konsumen budaya Arnould dan Thompson (2005),
Kekurang hati-hatian seorang Manajer didalam memberikan pelayanan akan memberi ruang serta berdampak pada upaya dan niat seorang pelanggan untuk melakukan switching (beralih), hal ini diakibatkan karena adanya persepsi pelanggan menjadi celah terbuka untuk melakukan hal tersebut. Antesenden yang menunjukkan bahwa hubungan Switching Cost dan loyalitas pelanggan akan menjadi lebih kuat ketika menghadirkan kepercayaan dan keyakinan yang tinggi, namun sebaliknya bila melihat adanya sebuah risiko yang dirasakan tinggi menciptakan turunnya tingkat kepercayaan menjadi lebih rendah atau bahkan hilang sama sekali. Namun, ada beberapa studi untuk mengidentifikasi dampak dari risiko yang dirasakan adanya hubungan yang mempengaruhi antara biaya beralih (Switching Cost) dan loyalitas pelanggan. Pelanggan yang loyal terhadap pelayanan yang telah ada akan berupaya untuk mengurangi upaya mencari penyedia baru, bahkan akan mencoba memberikan umpan balik positif kepada penyedia. Selain itu ada keyakinan yang kuat bahwa loyalitas memiliki hubungan dengan profitabilitas, ukuran (measure) bagi seorang pelanggan untuk melakukan switching. Singh (2006) juga menyatakan bahwa adanya rasa puas dari pelanggan merupakan faktor yang langsung mempengaruhi loyalitas untuk bertahan dipenyedia yang sama. Loyalitas, komitmen pelanggan untuk pembelian kembali, sangat berharga sebagai keunggulan kompetitif karena kesulitan perusahaan lain dalam mereplikasi ikatan (Kumar dan Shah, 2004).

Keputusan untuk melakukan pembelian menurut (Schiffman dan Kanuk, 2004 dalam Fajrianthi dan Farrah, 2005) pemilihan dari dua atau lebih alternatif pilihan keputusan pembelian, artinya bahwa 
seseorang dapat membuat keputusan, haruslah tersedia beberapa alternatif pilihan. Keputusan untuk membeli dapat mengarah kepada bagaimana proses dalam pengambilan keputusan tersebut itu dilakukan.

Gilliland dan Bello (2002) mengatakan stabilitas perilaku seorang pelanggan dipengaruhi oleh dua konstruk baik itu inertia dan calculative commitment untuk dapat mengulang pembelian meskipun memiliki persepsi negatif, dan mungkin juga menunjukkan perilaku oportunisti. Perilaku ini telah mendorong beberapa peneliti untuk membuat konsep yang berhubungan dengan gagasan yang berbeda-beda. Sebagai contoh, Zeelenberg dan Pieters (2004) berpendapat bahwa inertia suatu pelanggan "dapat disebabkan karena biaya yang relatif tidak tinggi dan keuntungan atau manfaat yang didapat". Evanschitzky et al. (2006) mengusulkan bahwa niat pelanggan untuk tetap dalam kerjasama yang dipengaruhi oleh faktor switching costs terjadi karena ikatan emosional (komitmen berkelanjutan), yang berkembang keluar dari stigma inertia. Studi yang mengatakan inersia merupakan sebuah konstruk yang mempengaruhi pelanggan, serta beberapa studi pemasaran bahwa hubungan telah dibangun di atas komitmen sebagai media dalam konteks relasional Gruen et al,(2000).

Beberapa pernyataan terkait penyedia mengatakan bahwa penyedia yang lebih kompetitif dan kuat adalah jika mereka mengembangkan hubungan jangka panjang, namun beberapa peneliti lain berpendapat bahwa tidak mutlak seluruh pelanggan yang mengembangkan pola pembelian jangka panjang memiliki motivasi untuk bertindak sebagai pelanggan yang benar-benar setia, namun dipengaruhi faktor inertia atau calculative commitment (Bozzo,2002).

Yanamandram dan White (2006) menyatakan bahwa hubungan antara kepuasan dengan loyalitas tidak terdefinisi dengan jelas. Menurut (Akerlund, 2005 dalam Ehrengren 2011), pendekatan dalam perspektif sebagai bagian dari risiko kerjasama atau "kemungkinan gagal", yang berarti tidak dapat memenuhi rencana dan sasaran karena konflik pada tingkat makro atau mikro. Model konflik kepentingan kami dapat diilustrasikan dengan dua lingkaran, satu lingkaran dalam dan satu lingkaran luar, di mana lingkaran dalam mewakili lingkungan konflik mikro atau konflik lingkungan kepentingan bisnis dan lingkaran luar mewakili lingkungan konflik makro atau konflik kerjasama bisnis.

Pada akhirnya penelitian ini bertujuan untuk memberikan perspektif penting dalam memperluas pengetahuan tentang inertia dan calculative commitment dengan cara menyelidiki sejauh mana tingkat perbedaan antara Inertia dan Calculative Commitment. Studi dalam penelitian ini mengusulkan analisia empiris melalui penelitian model yang menduga Switching Costs sebagai tahap awal bagi terciptanya inertia dan calculative commitment dalam konteks bisnis jasa layanan keuangan yaitu Perbankan. Zeelenberg dan Pieters (2004) berpendapat bahwa inertia bagi suatu pelanggan dapat disebabkan karena penalaran akan adanya persepsi di mana biaya lebih besar daripada manfaatnya.Loyalitas pelanggan dalam tahap afektif menyatakan bahwa antecedent dari loyalitas adalah kepuasan.

\section{Kerangka Konseptual}


Beberapa model yang diajukan oleh para pendapat ahli menjelaskan bahwa Switching Costs adalah hasil dari sebuah sikap yang dilakukan oleh pelanggan secara proaktif, sadar dan rasional melalui upaya tawaran dari penyedia dalam konteks hubungan bisnis, bahwa konsep dasar suatu Switching Costs upaya mempengaruhi Inertia bagi pelanggan untuk tetap bertahan dengan penyediayang sekarang. Mengenai jenis Switching Costs yang mempengaruhi inertia, Inder dan O'Brien (2003) menyatakan adanya ketidakpastian biaya cenderung menghasilkan reaksi psikologis tidak membuat nyaman pelanggan, pelanggan lebih keras menolak kehilangan sesuatu yang eksis. Dalam membuat keputusannya pelanggan selalu mempertimbangkan potensi kerugian dari pada memutuskan beralih dalam upaya untuk memperoleh keuntungan. (Kahneman dan Tversky, 1979).

Dari penjelasan diatas untuk lebih jelas dapat dilihat melalui Conceptual Framework di bawah ini:

Gambar Error! No text of specified style in document.-1 Kerangka Konseptual

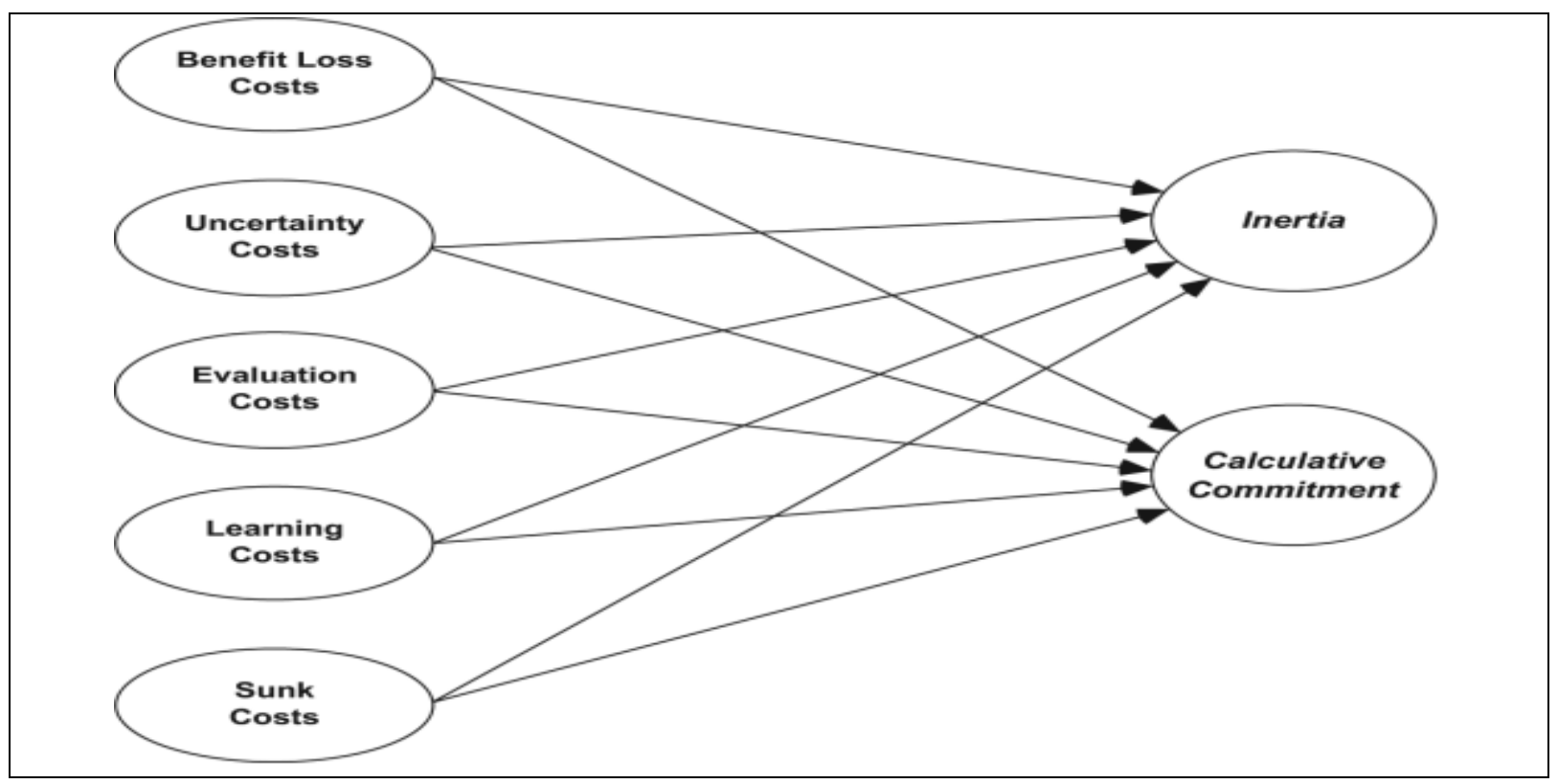

\section{B. Metode}

Desain penelitian adalah merupakan semua proses yang diperlukan dalam perencanaan dan pelaksanaan penelititan sejak dari perencanaan hingga pelaksanaan yang dilakukan secara terstruktur untuk mendapatkan sebuah jawaban atas pertanyaan-pertanyaan penelitian. Sekaran (2000) menyatakan bahwa desain penelitian didalamnya melibatkan sebuah urutan pilihan pengambilan keputusan rasional.

Penelitian yang penulis lakukan adalah menggunakan metode survey yang merupakan cara untuk mengumpulkan informasi secara luas dari kumpulan subjek yang diteliti. Unit analisis dalam penelitian ini adalah nasabah aktif pemilik rekening dalam sebuah bank. Penelitian ini diarahkan untuk menguji hipotesa yang menjelaskan pengaruh switching cost dengan lima indikatornya terhadap inertia dan calculative commitment.

Metode sampling yang digunakan dalam penelitian ini adalah Simple Random Sampling yaitu pengambilan sampel secara acak dan sederhana, dimana didalam 
pengambilan sampelnya setiap unsur yang membentuk populasi diberi kesempatan yang sama untuk terpilih menjadi sampel, cara ini akan sangat mudah apabila terdapat daftar lengkap unsur-unsur populasi. Prosedur yang cukup akurat untuk pengambilan sampel secara acak adalah dengan menggunakan tabel angka acak (Table of Random Numbers).

Populasi dari penelitian ini adalah nasabah pemilik rekening aktif di bank CIMB Niaga cabang fatmawati. Berdasarkan data yang telah didapatkan bahwa total nasabah di bank yang bersangkutan adalah 17.000, dengan jumlah kepemilikan rekening sebanyak 22.000 buah. Jumlah nasabah dan rekening tersebut adalah hasil merger antara Lippo dengan CIMB dengan menggabungkan beberapa cabang, seperti: cinere, pondok pinang, fatmawati dan terminal II bandara soekarnohatta

Terkait dengan survey yang dilakukan penulis, maka rumus untuk menentukan jumlah sampel minimum menurut Slovin dalam Husein Umar (2004) model untuk menentukan jumlah sampel minimum yang direncanakan adalah :

$$
n=\frac{N}{N \cdot d^{2}+1}
$$

Dimana $\mathrm{n}$ adalah ukuran sampel, $\mathrm{N}$ ukuran populasi dan d adalah tingkat kesalahan atau error.
Dalam penelitian ini jumlah sampel responden minimum yang direncanakan yaitu tingkat kepercayaan konsumen atau level of confidence terhadap jasa layanan keuangan adalah sebesar 95 persen atau nilai pada angka tabel distribusi $\mathrm{z}$ untuk tingkat kepercayaan atau level of confidence terhadap 5 (lima) indikator Switching Cost, dengan perhitungan:

$$
\begin{aligned}
& \mathrm{n}=\mathrm{N} /\left(\mathrm{N} \cdot \mathrm{d}^{\wedge} 2+1\right) \\
& \mathrm{n}=17,000 /\left(17,000 \cdot\left[(0.1)^{\wedge} 2+1\right)\right. \\
& \mathrm{n}=17,000 /(170+1) \\
& \mathrm{n}=17,000 / 171 \\
& \mathrm{n}=99.4152
\end{aligned}
$$

Populasi dari penelitian ini adalah pemilik rekening disebuah layanan jasa keuangan (Bank) dengan kepemilikan rekening sedikitnya sudah berjalan 3 (tiga) tahun, dengan latar belakang pendidikan dan merupakan seorang pekerja atau karyawan aktif..

\section{Discussion}

Dalam penelitian ini analisa Skewness dan Kurtosis merupakan suatu pengujian normalitas secara univarite untuk menguji kenormalan data masing-masing variabel penelitian, dimana suatu sampel dikatakan berdistribusi normal atau tidak.

Tabel Error! No text of specified style in document.-1 Pengujian Normalitas

\begin{tabular}{|c|l|c|c|c|c|c|}
\hline No & Variabel & & Statistic & $\begin{array}{c}\text { Std. } \\
\text { Error }\end{array}$ & $\mathrm{z}$ & Keputusan \\
\hline 1 & Benefit loss cost & Mean & 2.776 & 0.047 & & \\
\hline & & Skewness & 0.301 & 0.184 & 1.622 & Normal \\
\hline & & Kurtosis & -0.174 & 0.366 & -0.468 & Normal \\
\hline
\end{tabular}




\begin{tabular}{|c|c|c|c|c|c|c|}
\hline 2 & $\begin{array}{l}\text { Uncertainty/ } \\
\text { Economic risk cost }\end{array}$ & Mean & 3.218 & 0.035 & & \\
\hline & & Skewness & -0.247 & 0.184 & -1.330 & Normal \\
\hline & & Kurtosis & 0.635 & 0.366 & 1.709 & Normal \\
\hline \multirow[t]{3}{*}{3} & Evaluation cost & Mean & 3.353 & 0.043 & & \\
\hline & & Skewness & 0.129 & 0.184 & 0.697 & Normal \\
\hline & & Kurtosis & 0.530 & 0.366 & 1.428 & Normal \\
\hline \multirow[t]{3}{*}{4} & Learning cost & Mean & 3.415 & 0.044 & & \\
\hline & & Skewness & -0.003 & 0.184 & -0.018 & Normal \\
\hline & & Kurtosis & 0.577 & 0.366 & 1.553 & Normal \\
\hline \multirow[t]{3}{*}{5} & Sunk cost & Mean & 3.652 & 0.055 & & \\
\hline & & Skewness & -0.248 & 0.184 & -1.337 & Normal \\
\hline & & Kurtosis & 0.430 & 0.366 & 1.158 & Normal \\
\hline \multirow[t]{3}{*}{6} & Inertia & Mean & 3.539 & 0.046 & & \\
\hline & & Skewness & 0.136 & 0.184 & 0.735 & Normal \\
\hline & & Kurtosis & -0.075 & 0.366 & -0.202 & Normal \\
\hline \multirow[t]{3}{*}{7} & $\begin{array}{l}\text { Calculative } \\
\text { commitment }\end{array}$ & Mean & 3.080 & 0.038 & & \\
\hline & & Skewness & 0.144 & 0.184 & 0.775 & Normal \\
\hline & & Kurtosis & 0.187 & 0.366 & 0.503 & Normal \\
\hline
\end{tabular}

Berdasarkan tabel di atas terlihat hasil pengujian normalitas dengan skewness dan kurtosis semua variable terlihat memiliki nilai zskewness dan kurtosis lebih kecil dari 2.56, sehingga semua item dari variablevariabel tersebut dapat dikatakan berdistribusi normal.

Pengujian hipotesis dilakukan dengan melihat nilai signifikansi dari setiap hubungan. Level of significance $(\alpha)$ yang ditetapkan adalah sebesar 5\%, yang berarti bahwa batas toleransi kesalahan yang dapat ditolerir adalah sebesar 5\%. Dengan kata lain, level of confidence dari pengujian hipotesis ini adalah sebesar 95\%. Apabila pvalue $<0,05$, maka dapat dikatakan bahwa variabel independen terdapat pengaruh yang signifikan terhadap variabel dependen 
Tabel Error! No text of specified style in document.-2 Hasil Uji Koefisien Determinasi Variabel Dependen Inertia

Model Summary

\begin{tabular}{|l|r|r|r|r|}
\hline Model & \multicolumn{1}{|c|}{$\mathrm{R}$} & $\mathrm{R}$ Square & $\begin{array}{c}\text { Adjusted } \\
\text { R Square }\end{array}$ & $\begin{array}{r}\text { Std. Error of } \\
\text { the Estimate }\end{array}$ \\
\hline 1 & $.426^{\mathrm{a}}$ & .182 & .157 & .55573 \\
\hline
\end{tabular}

a. Predictors: (Constant), Sunk cost, Learning cost, Benefit loss cost, Uncertainty/Economic risk cost, Evaluation cost

Dari tabel di atas, dapat dilihat bahwa koefisien (r) yaitu sebesar 0.426. nilai tersebut menunjukkan bahwa korelasi atau hubungan antara variabel (Benefit loss costs, Uncertainty/Economic risk costs, Evaluation costs, Learning costs, Sunk costs) dengan inertia dinyatakan memiliki hubungan yang lemah dikarenakan memiliki nilai korelasi < 0.50 .

Sedangkan nilai Adjusted R Square (koefisien determinasi) dihasilkan angka sebesar 0.157 yang berarti bahwa variasi variabel inertia dapat dijelaskan oleh variabel (Benefit loss cost, Uncertainty/Economic risk cost, Evaluation cost, Learning cost, Sunk cost) adalah sebesar 0.157 atau sebesar $15.7 \%$ sedangkan sisanya sebesar $84.3 \%$ dijelaskan oleh faktor-faktor lain yang tidak terdapat dalam penelitian ini.

Tabel Error! No text of specified style in document.-3 Hasil Uji Koefisien

Determinasi Variabel Dependen Calculative Commitment

Model Summary

\begin{tabular}{|l|r|r|r|r|}
\hline Model & $\mathrm{R}$ & $\mathrm{R}$ Square & $\begin{array}{c}\text { Adjusted } \\
\text { R Square }\end{array}$ & $\begin{array}{r}\text { Std. Error of } \\
\text { the Estimate }\end{array}$ \\
\hline 1 & $.404^{\mathrm{a}}$ & .163 & .138 & .47020 \\
\hline
\end{tabular}

a. Predictors: (Constant), Sunk cost, Learning cost, Benefit loss cost, Uncertainty/Economic risk cost, Evaluation cost

Dari tabel di atas, dapat dilihat bahwa koefisien (r) yaitu sebesar 0.404. nilai tersebut menunjukkan bahwa korelasi atau hubungan antara variabel (Benefit loss costs, Uncertainty/Economic risk costs, Evaluation costs, Learning costs, Sunk costs) dengan Calculative commitment dinyatakan memiliki hubungan yang lemah dikarenakan memiliki nilai korelasi $<0.50$, sedangkan nilai Adjusted $\mathrm{R}$ Square (koefisien determinasi) dihasilkan angka sebesar 0.138 yang berarti bahwa variasi variabel Calculative commitment dapat dijelaskan oleh variabel (Benefit loss costs, Uncertainty/Economic risk cosst, Evaluation costs, Learning costs, Sunk costs) adalah sebesar 0.138 atau sebesar $13.8 \%$ sedangkan sisanya sebesar $86.2 \%$.

Uji Regresi 
Tabel Error! No text of specified style in document.-4 Hasil Perhitungan Regresi

\begin{tabular}{|c|l|c|c|c|c|}
\hline No & \multicolumn{1}{|c|}{ Model } & Beta & $\mathrm{t}$ & Sig. & Keputusan \\
\hline 1a & Benefit loss cost $\rightarrow$ Inertia & 0.054 & 0.742 & 0.459 & $\begin{array}{c}\text { Ho } \\
\text { ditolak }\end{array}$ \\
\hline 1b & $\begin{array}{l}\text { Uncertainty/Economic risk } \\
\text { cost } \rightarrow \text { Inertia }\end{array}$ & 0.031 & 0.423 & 0.673 & $\begin{array}{c}\text { Ho } \\
\text { ditolak }\end{array}$ \\
\hline 1c & Evaluation cost $\rightarrow$ Inertia & 0.257 & 3.410 & 0.001 & Ho diterima \\
\hline $1 \mathrm{~d}$ & $\begin{array}{l}\text { Learning cost } \rightarrow \text { Inertia } \\
\text { 1e }\end{array}$ & 0.235 & 3.159 & 0.002 & Ho diterima \\
\hline 2ank cost $\rightarrow$ Inertia & $\begin{array}{l}\text { Benefit loss cost } \rightarrow \\
\text { Calculative commitment }\end{array}$ & 0.142 & 1.939 & 0.054 & Ho ditolak \\
\hline 2b & $\begin{array}{l}\text { Uncertainty/Economic risk } \\
\text { cost Calculative } \\
\text { commitment }\end{array}$ & -0.010 & -0.133 & 0.894 & Ho ditolak \\
\hline 2c & $\begin{array}{l}\text { Evaluation cost } \\
\text { Calculative commitment }\end{array}$ & 0.104 & 1.361 & 0.175 & Ho ditolak \\
\hline 2d & $\begin{array}{l}\text { Learning cost } \\
\text { Calculative commitment }\end{array}$ & 0.227 & 3.021 & 0.003 & Ho diterima \\
\hline 2e & $\begin{array}{l}\text { Sunk cost } \rightarrow \text { Calculative } \\
\text { commitment }\end{array}$ & 0.239 & 3.380 & 0.001 & Ho diterima \\
\hline
\end{tabular}

Hasil penelitian berdasarkan hipotesis 1a dalam penelitian ini, tidak ada pengaruh yang signifikan antara variabel Benefit loss costs terhadap inertia. Ada kekhawatiran bagi nasabah untuk berpindah kepenyedia jasa lainnya akan hilangnya benefit atau keuntungan.

Hasil penelitian ini tidak konsisten dengan penelitian sebelumnya oleh Inder and (Jone et al didalam Perera and Kim, 2007), yang dalam penelitiannya bahwa variabel Sunk costs tidak berpengaruh terhadap Inertia dengan nilai koefisien beta sebesar 0.14 .

Hasil penelitian berdasarkan hipotesis $1 \mathrm{~b}$ dalam penelitian ini, tidak ada pengaruh yang signifikan antara variabel Uncertainty/Economic risk cost terhadap inertia. Ada kekhawatiran dan keraguan bagi nasabah untuk berpindah ke penyedia jasa lainnya akan tidak didapatnya keuntungan, tidak mendapatkan pelayanan yang lebih baik dari sebelumnya. 
Hasil penelitian ini tidak konsisten dengan penelitian sebelumnya oleh Jones et al (2003) yang dalam penelitiannya bahwa variabel Uncertainty/Economic risk cost tidak berpengaruh terhadap Inertia dengan koefisien beta sebesar 0.01 .

Hasil penelitian berdasarkan hipotesis 1c dalam penelitian ini, ada pengaruh yang signifikan antara variabel evaluation costs terhadap inertia. Kekhawatiran para nasabah untuk berpindah ke pengguna jasa lainnya karena beberapa penyebab, seperti: keengganan nasabah untuk mempelajari, membandingkan serta mengorbankan waktu untuk mempelajari sebuah penawaran yang baru.

Hasil penelitian ini konsisten dengan penelitian sebelumnya oleh Jones et al (2003) yang dalam penelitiannya bahwa variabel evaluation cost berpengaruh signifikan terhadap Inertia dengan koefisien beta sebesar 0.36 .

\section{Conclussion}

Beberapa hal yang harus diperhatikan oleh para manager bank dalam meningkatkan dan membangun hubungan dan kepercayaan kepada nasabah, harus memperhatikan dan mengenali dengan baik tingkah laku dan harapan konsumen atau nasabah antara lain: (1) Penyedia jasa dapat mampu menciptakan sebuah produk jasa yang kompetitif yang mampu menarik minat konsumen untuk beralih kepada produk yang diciptakan. (2) Peran manajer didalam sebuah perusahaan penyedia jasa adalah tantangan untuk mempertahankan jumlah nasabah yang setia terhadap produk keluaran yang dihasilkan. (3) Dalam rangka memperoleh keuntungan yang signifikan penyedia jasa harus mampu menalisa perilaku serta karakteristik konsumen sebagai dasar didalam mendevelope suatu produk yang dapat memenuhi harapan nasabah.

\section{Reference}

Arnould, Eric J. and Thompson, Craig J., (2005), "Consumer Culture Theory (CCT): Twenty Years of Research”, Journal of Consumer Research, Vol. 31, No. 4 (March 2005), pp. 868-882

Baron, S., and Harris, K., "Toward an understanding of consumer perspectives on experiences:, (2010), Journal of Services Marketing 24/7 (2010) 518-531

Bozzo, Cecille., (2002), "Understanding Inertia in an Industrial Context", Journal of Customer Behaviour, 2002, 1, 335-355.

Fajrianthi dan Farrah, (2005), "Strategi Perluasan Merek dan Loyalitas Konsumen”, INSAN Vol. 7 No. 3, Desember 2005, Fakultas Psikologi Universitas Airlangga.

Ehrengren, I. and Ho"rnsten, B,. (2011), "Performance and risk management in strategic cooperation". Journal of Productivity and Performance Management, Vol. 60 Iss 4 pp. $387-403$.

Gilliland, David I.and Daniel C. Bello, Daniel C., "Two Sides to Attitudinal Commitment: The Effect of Calculative and Loyalty Commitment on Enforcement Mechanisms in Distribution Channels", Journal of the Academy of the Marketing Sciences, 30 (1), 24-43. 
Godkin, L (2010) "The zone of inertia: absorptive capacity and organizational change", Learning Organization, The, Vol. 17 Iss: 3, pp.196 - 207.

Gruen, Thomas W, Osmonbekov, Talai, Czaplewski, (2006), "eWOM: The impact of customer-to-customer online know-how exchange on customer value and loyalty", Journal of Business Research 59 (2006) 449 - 456.

Heinonen, K, Strandvik, T and Mickelsson, Karl-Jacob (2010), “A customer-dominant logic of service”, Journal of Service Management, 21 (4), 531-548.

Kumara, V and Shahb, S, (2004), "Building and sustaining profitable customer loyalty for the 21st century”, Journal of Retailing, 80 (4), 317-329

He, Yanqun \& Tse, Siu The role of switching costs on service loyalty: a canonical correlation analysis Journal of Chinese Entrepreneurship, Vol. 1 Iss 2 pp. $154-164$.

Heiner, E, Gopalkrishnan R., Iyer, GR, Plassmann, Niessing, Meffert (2006)," The relative strength of affective commitment in securing loyalty in service relationships", Journal of Business Research 59 (2006) 1207-1213

Hooland, S.V, Vandooren, F.O and Mendez Rodriguez, E (2010), "Opportunities and risks for libraries in applying for European Opportunities and risks for libraries in applying for European funding" The Electronic Library Vol. 29 No. 1, pp. 90-104.

Jena, S., Guin, K.K, Dash, S.B., (2011) "Effect of relationship building and constraint-based factors on business buyers' relationship continuity intention A study on the Indian steel industry", Journal of Indian Business Research, Vol. 3 No. 1, 2011 pp 22-42.

Jones, T., Fox Shirley, F. Taylor and Leandre R. Fabrigar, (2010), “ Service customer commitment and response”, Journal of Services Marketing 24/1 (2010) 16-28

Mitchell, C., Imrie Brian C., (2009) "Consumer tribes: membership, consumption and building loyalty", Asia Pacific Journal of Marketing and Logistics Vol. 23 No. 1, pp. 39-56.

Michael D. Clemes, Christopher Gan and Dongmei Zhang, (2009), "Customer switching behaviour in the Chinese retail banking industry”, International Journal of Bank Marketing Vol. 28 No. 7, pp. 519-546

Mohd Kassim, Norizan and Abdulla, Abdel Kader Mohammed Ahmed (2006), "The influence of attraction on internet banking: an extension to the trust-relationship commitment model", International Journal of Bank Marketing, 24 (6), 424-442

Nusair, K. Hua and $\mathrm{Li}, \mathrm{Xu}$, (2010) "A conceptual framework of relationship commitment: $e$ travel agencies", Journal of Hospitality and Tourism Technology Vol. 1 No. 2, pp. 106-120. 
Yanamandram, V. and White, L.(2010) "Are inertia and calculative commitment distinct constructs? An empirical study in the financial services sector" International Journal of Bank Marketing, Vol. 28 No. 7, 2010 pp. 569-58

Yuan, Lin and Pangarkar, $N$ (2010) "Inertia versus mimicry in location choises by Chinese multinationals", Internasional Marketing Review, Vol. 27 ISS: 3, pp.295 - 315.

Yen, Y.S, (2009), "Can perceived risks affect the relationship of switching costs and customer loyalty" Internet Research, Vol. 20 No. 2, pp. 210-224.

Valenzuela, F, " Switching barriers used to retain retail banking customers Some empirical evidence from a South American country”, (2010), Management Research Review Vol. 33 No. 7, pp. 749-766.

Zeelenberg, M.; Pieters, R, (2004) “Beyond valence in customer dissatisfaction”, Published in: JBR: Journal of Business Research

Zhao, L.A. and Nicole Koenig-Lewis, (2009), "Adoption of internet banking services in China: is it all about trust?, International Journal of Bank Marketing Vol. 28 No. 1, pp. 7-26 